\title{
Erratum to: Creating Temporary Pools as Wetland Mitigation: How Well Do They Function?
}

M. B. Kolozsvary ${ }^{1}$ M. A. Holgerson ${ }^{2}$

Published online: 26 April 2016

(C) Society of Wetland Scientists 2016

Erratum to: Wetlands

DOI 10.1007/s13157-016-0742-y

'The caption for Appendix 1. should read "Appendix 1. Seasonal sampling of water chemistry and algal biomass in created (black circles) and reference (gray triangles) pools."

The online version of the original article can be found at http://dx.doi.org/ 10.1007/s13157-016-0742-y.

M. B. Kolozsvary

mkolozsvary@siena.edu

1 Department of Environmental Studies and Sciences, Siena College, Loudonville, NY 12211, USA

2 School of Forestry and Environmental Studies, Yale University, New Haven, CT 06511, USA 